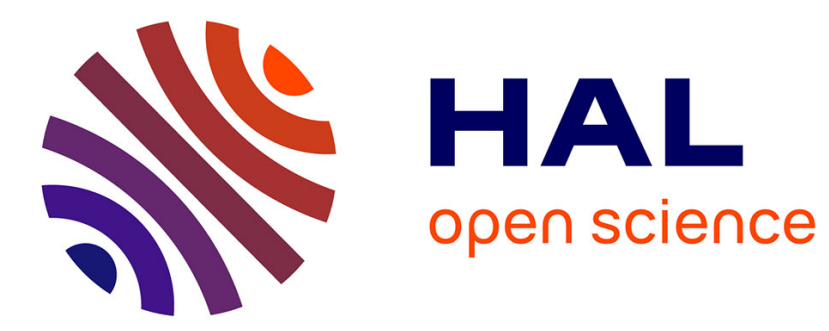

\title{
Design for additive manufacturing (DfAM) methodologies: a proposal to foster the design of microwave waveguide components
}

Mathieu François, Frédéric Segonds, Mickaël Rivette, Simon Turpault, Patrice Peyre

\section{To cite this version:}

Mathieu François, Frédéric Segonds, Mickaël Rivette, Simon Turpault, Patrice Peyre. Design for additive manufacturing (DfAM) methodologies: a proposal to foster the design of microwave waveguide components. Virtual and Physical Prototyping, 2019, 14 (2), pp.175-187. 10.1080/17452759.2018.1549901 . hal-02447632v2

\section{HAL Id: hal-02447632 \\ https://hal.science/hal-02447632v2}

Submitted on 14 Dec 2020

HAL is a multi-disciplinary open access archive for the deposit and dissemination of scientific research documents, whether they are published or not. The documents may come from teaching and research institutions in France or abroad, or from public or private research centers.
L'archive ouverte pluridisciplinaire HAL, est destinée au dépôt et à la diffusion de documents scientifiques de niveau recherche, publiés ou non, émanant des établissements d'enseignement et de recherche français ou étrangers, des laboratoires publics ou privés. 


\section{Design for additive manufacturing (DfAM) methodologies: a proposal to foster the design of microwave waveguide components}

Mathieu François, Frédéric Segonds, Mickaël Rivette, Simon Turpault \& Patrice Peyre 


\title{
Design for additive manufacturing (DfAM) methodologies: a proposal to foster the design of microwave waveguide components
}

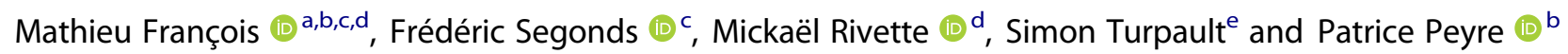

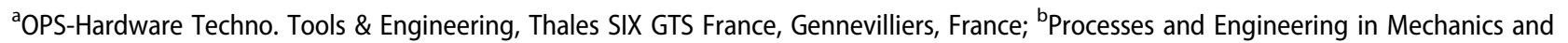 \\ Materials Laboratory (PIMM), UMR CNRS 8006 / Arts et Métiers ParisTech / CNAM, Paris, France; 'Product Design and Innovation Laboratory \\ (LCPI), Arts et Métiers ParisTech, Paris, France; ${ }^{d}$ Manufacturing Engineering and Control Laboratory (LCFC), Arts et Métiers ParisTech, Metz,

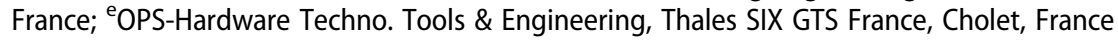

\begin{abstract}
Additive manufacturing offers many advantages, especially in terms of creativity and design freedom. However, this emerging technology is disrupting the way design is carried out and creativity is often limited by the cognitive barriers installed through years of traditional manufacturing processes. Likewise, as this manufacturing process is relatively recent and quite unknown to designers, its specificities are not always considered during the design phase, which leads to manufactured parts happening to differ from CAD models in terms of sizing or surface quality. Consequently, microwave components nowadays manufactured layer-by-layer do not exhibit operational electromagnetic performances. In this way, it is necessary to guide designers throughout the development of a product by drawing their attention to the different steps they must consider in order to design an additive manufactured optimised part.
\end{abstract}

\section{Introduction}

For many years, microwave waveguide components have been used in communication systems and especially for antenna-feed chains. This RadioFrequency (RF) type of equipment is already widely operational in different fields such as satellite communications (SatCom), radars, space observations etc. due to their advantages in terms of low losses as well as their high energy management capabilities. In the recent years, several institutions and industries have been showing growing interest in additive manufacturing (AM) process for waveguide components (Booth and Lluch 2017; Peverini et al. 2017; Tchoffolo-Talom and Turpault 2017). One of the greatest promises of $A M$ can be found in exploiting the extra degrees of freedom it offers to achieve innovative design configurations unachievable by conventional techniques (Laverne, Segonds, and Dubois 2016). However, additive technologies impose specific decisions - such as orientation, part topology, support structures, materials and so on - that designers must consider during the design development to ensure an optimised part. The complexity of designing for additive manufacturing (DfAM) lies in the interdependence of these rules. It is therefore essential that the design method integrates all of this knowledge to guide designers in their choices suitable to their purpose. But how to foster microwave waveguide component design by the use of a DfAM method? This paper proposes a DfAM method that can closely guide designers in the design of additive manufactured microwave parts. In chapter two, a literature review has been carried out that we use to highlight our motivations in chapter three. Then, in chapter four, a new method for additive manufacturing RF part components fabricated by Laser Beam Melting process is proposed, followed in chapter five by the development of a three-port Kaband waveguide power divider as a case study. Conclusions and orientations of future research will bring to a close.

\section{Literature review}

First, a review of the current state of practice in $A M$ is introduced to evaluate the manufacturing specificities to be taken into account particularly when dealing with electromagnetic requirements, followed by a presentation of its application to microwave waveguide components. Then, the different approaches employed to perform design for AM are analyzed. 


\subsection{Additive manufacturing}

\subsubsection{Specific geometrical considerations}

Support structures are among specificities of certain additive processes, including powder bed technologies. Their main use lies in supporting overhanging volumes to avoid a gravity-induced melt-pool collapse (Hussein et al. 2013). They are to be placed underneath every surface that is inclined by less than a critical angle, ranging from 20 to 45 degrees towards the build platform (Leary et al. 2014; Thomas 2009; Vandenbroucke and Kruth 2007). For Laser Beam Melting process, supports also play a role of a heat sink, as a huge amount of thermal energy in led into the build area by the laser. To prevent residual stress from remaining after cooling and to avoid an increase of thermal stress inside the part, support structures act as a heat dissipater to transfer the heat to the manufacturing platform (Thomas 2009). Consequently, the impact of residual stress on the process is reduced. However, microwave components being related to pipes, once the fabrication of the part is completed, every support structure placed inside cavities is trapped and impossible to remove which would prevent the signal from being transmitted.

Otherwise, although manufacturing dimensional tolerances manage to be met and repeated by the use of conventional techniques, these considerations are much more complex for additive processes. Actually, their mastery is not total and it is still difficult to know and anticipate these dimensional variations (Kempen 2014; Kniepkamp, Fischer, and Abele 2016). In the RF domain, these variations are a major concern. For example, a variation of 200 microns of the crosssection - i.e $2 \%$ of the dimensions - can cause a $0.5 \mathrm{GHz}$ offset on a bandwidth target of $1.5 \mathrm{GHz}$ (Kaband as defined by IEEE Std 521-1984).

\subsubsection{Part orientation}

Layer-by-layer manufacture inevitably induces a 'staircase effect', owing to the finite layer thickness. This effect is all the more important for the surfaces that are neither orthogonal nor parallel to the manufacturing platform. The arithmetic roughness, Ra, generated by this geometric phenomenon can be modelled according to the formula (Strano et al. 2013):

$$
R_{a}=\frac{1}{L} \int_{0}^{L}|y(x)| \mathrm{d} x=\frac{1}{4} L_{t} \cos \alpha
$$

where $L_{t}$ represents the layer thickness and $a$ the angle between the manufacturing platform and the surface of the part.
However, this geometrical model seems far from representing the real surface quality obtained on a fabricated part (Canellidis, Giannatsis, and Dedoussis 2009). It can be explained by the fact that physical phenomena cropped up during manufacture (powder aggregates) are not taken into account. However, the actual state of knowledge of the scientific community concerning these phenomena does not currently allow the construction of a mathematical model to accurately predict the surface finish.

In this context, the higher the roughness and the higher the surface resistance, resulting in power loss and attenuation constant raises (Wang and Cui 2011). In addition, as the frequency goes up, this phenomenon is getting bigger because the surface currents are closer to the (rough) surface and so the electric path becomes longer. Power loss can be increased by $60 \%$ compared to the same smooth surface when the average quadratic roughness is equal to skin depth (Morgan 1949).

According to the distribution of the induced currents for the fundamental $T E_{10}$ propagation mode in a rectangular waveguide (Figure 1), we assume that the roughness on the larger surfaces has a bigger impact on the RF performances - both in terms of loss and frequency offset - than on smaller ones. Consequently, as it is often difficult to find a manufacturing orientation which could minimise the roughness on all the surfaces, the surfaces of width 'a' (Figure 1) should be worthy of more attention. Thereafter, in order to well distinguish the relative impact of each rough surface on the attenuation, the surfaces of width ' $a$ ' will be named the functional surfaces of the first order (FSFO) - as we assume that roughness of these surfaces have a more significant impact - whereas the surfaces of width ' $b$ ' will be called the functional surfaces of the second order (FSSO), as shown in Figure 1.

However, surface finish in production is currently not fully controlled. To try to get the best surface finish possible - without considering post treatments - various experimental measurements have been made. This has

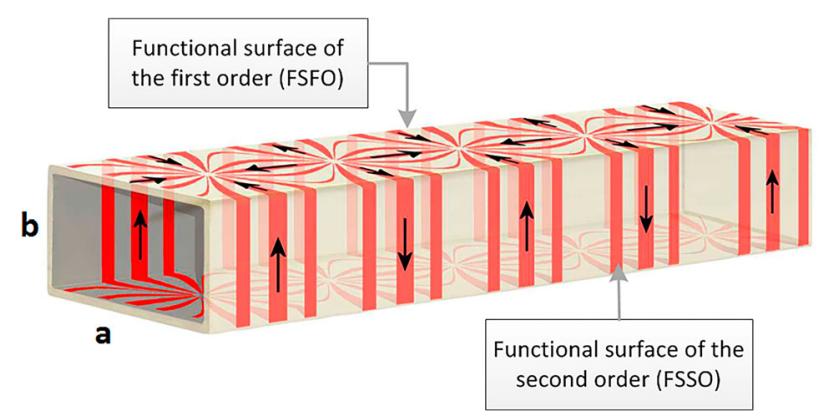

Figure 1. Definition of the functional surfaces of the first (FSFO) and second order (FSSO). 
led to preferred orientation trends for manufacturing (Canellidis, Giannatsis, and Dedoussis 2009; Thomas 2009).

\subsection{Microwave waveguide components made in additive manufacturing}

\subsubsection{Theoretical interest in additive manufacturing}

Since the technology can manufacture parts in a continuous way, it is then possible to dispense with assemblies and therefore interfaces - which induce, among others, an increase in insertion loss and thus a degradation of the signal. Also, AM technologies provide superior geometric freedom and can free engineers from many mechanical constraints. Beyond simply trying to redesign existing models, it would be very interesting to exploit this design opportunity by developing complex geometries that could improve RF performances, leading to lower power loss and wider bandwidth.

\subsubsection{Practical limitations}

Consequently, a great deal of research has been done in order to evaluate the electro- magnetic performances of additively manufactured microwave waveguide components such as waveguides and filters (TchoffoloTalom and Turpault 2017; Zhang and Zirath 2015). What emerges from these microwave-specific studies can be summarised by frequency shifts and signal amplitude loss compared to simulations, more or less important depending on the frequency band used. To try to explain these results, many factors - more or less verified - are brought up. Among them, dimensional tolerances of manufacture, conductivity, and roughness are widely introduced and seem to have a bigger influence. However, most of these studies focus on components whose design is very often similar to those drawn for conventional manufacturing.

In that way, other researches exploiting geometric opportunities have been performed: spherical and ellipsoidal cavities have replaced rectangular ones (Booth and Lluch 2017; Guo et al. 2015), stubs have been leaned to fit for AM (Peverini et al. 2017) and holes have been introduced into the thickness to lighten the waveguide (Rojas-Nastrucci et al. 2016). Although the theoretical quality factor is increased with these new geometries, frequency shifts and an overall increase in loss are still observed. It seems to show that manufacturing constraints are not controlled enough. Thus, the limitations induced by $A M$ are not fully considered during the design stage, which could partly explain the performances observed.

\subsection{Design methods for $A M$ components}

Analysis of existing work through the literature reveals the lack of effective methods of design support for additive manufacturing:

(1) First, the inadequacy of effective methods of design assistance for additive manufacturing is observed. Most of them propose a sequential approach: design process, manufacturing strategy, and manufacturing. The knowledge of the process is examined independently at each step, through the use of generic rules, favouring the 'over the wall' effect. As a result, those compartmentalised methods cannot take full advantage of AM;

(2) Second, some categories are underdeveloped compared to others which lead to unbalanced considerations during the design process.

(3) Third, design rules and design guidelines are specific to a process and material so inexperienced designers are quite restricted in their decisions.

(4) Forth, methods often focus on a single optimisation parameter such as weight reduction or surface roughness while AM can potentially optimise much more simultaneously.

(5) Last, creativity is not enough encouraged during the design development and is consequently limited by the psychological inertia of conventional process restriction (Laverne et al. 2014). Thereby, specific geometries caused by manufacturability limitations should not be considered too early in the design stage (Kumke et al. 2016).

As such, how to establish a multifunctional method of Design for Additive Manufacturing while integrating the functional requirements specific to microwave guided components some of whom seem limited by additive manufacturing?

The integrated approach seems to correspond to AM because it is enough flexible to accept the interdependence of the specific rules. Design of the part is no longer constrained by the process but in keeping with the benefits of additive manufacturing. Ideal geometry comes from both the constraints of the specifications and knowledge of the chosen process. We decided to base our method on Pahl and Beitz approach, by integrating the right tools at the right time (Pahl and Beitz 2007). This global concept allows designers to have an overview of the decisive choices in connection with $A M$ they must perform throughout the design process. 


\section{DfAM method proposal}

Based on the requirement list established in the previous section, we developed a DfAM framework trying to incorporate every step necessary for the good integration of additive manufacturing opportunities and limitations. This approach is shown in Figure 2.

\subsection{Framework}

According to Laverne's DfAM classification, the proposed method is part of the DfAM for concept assessment (Laverne et al. 2014). In addition, in accordance with the general development and systematic design procedure described by Pahl and Beitz, the suggested frame- work is divided into 4 major phases namely: problem analysis, conceptual design, embodiment design, and detail design. Then each of these phases is made up of one or several modules: task clarification and definition of requirements, preliminary study, void conceptual design, mechanical and thermal casing, and finally simulation analysis. Finally, each module is subdivided into a number of working groups within existing tools and methods are put (manufacturing process selection, design guidelines, design rules, geometrical validation etc.).

\subsection{Directions for use}

This section details the way of comprehending the design process and the different decision-making modules.

\subsubsection{Task clarification and definition of requirements}

The first step is based on the general concept of the traditional task clarification and definition of requirements phase of systematic engineering design process. It deals with the technical specifications, function tree, preliminary studies, external analysis etc. based on existing methods developed by (Eder and Hubka 1996; Hirtz et al. 2002; Pahl and Beitz 2007; Ulrich and Eppinger 2003).

Functional specifications constitute for the design department a background document from which it will be possible to build a technical chart and a breakdown of tasks (ISO/IEC/IEEE). From the formulation of a desired functional state, the project management group must be able to define a specified or required state. This is done only after having imagined all the technical solutions (possible variants) answering the service functions initially desired. This leads to a function tree. The enumeration of the previous functions serves first of all to imagine the various possible technical solutions, then to carry out a feasibility study aimed at selecting the best solution in relation to the requirements. From the statement of all these solutions and technological characteristics, an understanding will have to be found to retain the main subsystems of each function, which is the object of a selection with justifications of exclusions, resulting in the functional specifications (ISO/IEC/IEEE). Finally, a coefficient of flexibility determines the importance of considering the various sub criteria with respect to the product to be obtained. As can be seen, this functional approach allows a challenge or a technological innovation of the project, while taking into account the future operating environment of the product. The simple logic of decomposition of the constitutive products would not allow such emergence of new ideas. Also, the external analysis needs to be examined at this stage. Flows between environmental elements (temperature, humidity level, etc.) and the product requirements to be studied: it will definitely have an influence on the process selection and sizing. Once the technical specifications are completed, the structural ones are reviewed by performing at least three major analyses. The specified state of the system, resulting from the functional decomposition (Pahl and Beitz 2007), will allow the various actors of the project to more easily apprehend any complex product, and thus to manage it in a more efficient way. The resulting representation is a 'breakdown structure' (National Aeronautics and Space Administration 1994), whose decomposition has to be detailed up to levels allowing an optimised realisation of all the system elementary functions. Through a matrix structure, it is possible to match the two flowcharts (technical and functional). This will serve as a basis for operating safety by listing all the elements of the system involved in the satisfaction of a particular function, and by controlling the effects of modifying one of these elements on all the functions concerned. In addition, the flows associated with the overall function performance of the product are drawn up. To do so, a classification of functional basis and flows sets are proposed by Hirtz et al. (2002). The definition of flows will affect the material, the shape and sizing (Sossou et al. 2018). Finally, functional interfaces (FI) which are characterised by the relationship that two spatial regions must have to fulfil a function must be assessed. According to (Sossou et al. 2018), they can be of three different natures: contact-free (for example heat dissipation), non-permanent (button, lever, etc.) or part-to-part contact. Those kinds of interactions will have an influence especially on the design space and mechanical constraints. The last working group within the task 


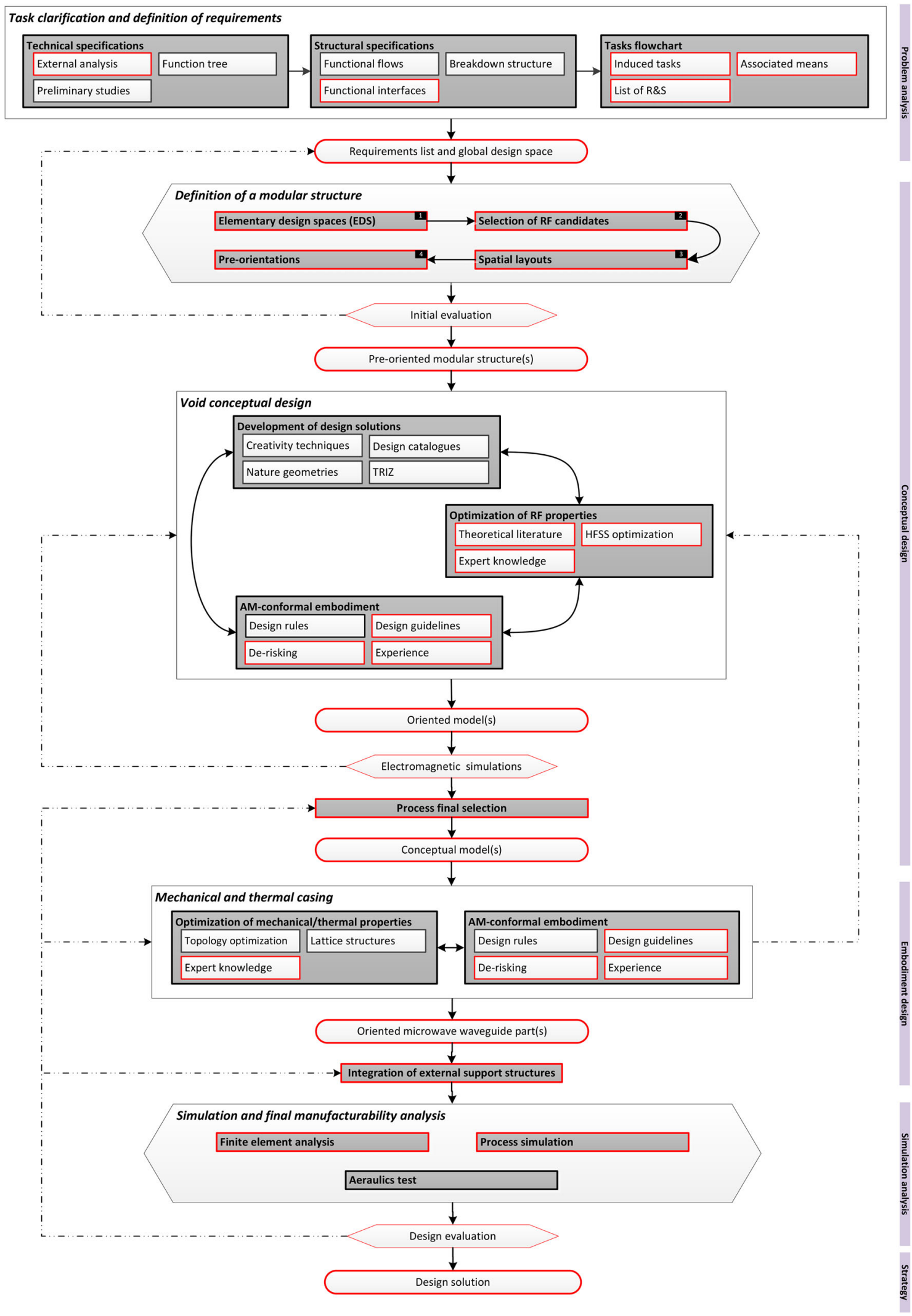

Figure 2. Design for Additive Manufacturing method proposal applied to microwave waveguide components fabricated by Laser Beam Melting process (in red the path followed in the case study). 
clarification and definition of requirements module consists in defining the task flowchart. This last division, also called technical chart, results from the product tree and defines the set of:

(1) Tasks induced by the product decomposition;

(2) Associated resources necessary for the study and production of the product and sub products (but absent in the final product);

(3) List of requirements and specifications (R\&S) to be taken into consideration throughout the project.

The technical chart is used for planning all the activities and means necessary for the good progress of the project according to the requirements and specifications of the need. A product induced task matrix can be introduced to overcome any forgetfulness as to the work to be done and on the other hand to group tasks. Once the whole requirement list and the global design space are established, preliminary studies can start.

\subsubsection{Definition of modular structures}

This second module is composed of four working groups, namely: elementary design spaces, selection of RF candidates, spatial layouts and pre-orientations.

Through the decomposition into elementary functions (waveguide, filter, polariser, orthomode, etc.) of the global function, it is possible to define a coarse design space for each of them. The dimensions of those Elementary Design Spaces (EDS) rely on the frequency band - but it is important to mention that some of them are not fixed due to their additional degrees of freedom such as length or bending ability. The objective here is not to fix the final geometry of these functions, but to draw a primary representative idea of the dimensions. In the next stages, those elementary design spaces will be 'carved' to get an optimised geometry. Note that functions integrations should be considered here.

By means of these representations, RF candidate parts - associated with an elementary function - are selected. This can be done by considering the dimensions of the part with the selected machines, specific desired characteristics in some regions incompatible with the AM technology, different materials for some parts, etc. If there are no obvious incompatibilities, the objective is to settle on all the elementary functions that compose the global function and run the third step.

Then, the RF selected parts - and thus the elementary design spaces - are pre-oriented and spatially arranged within the global design space to bring out the primary design of the global function. To do so, some considerations must be taken on board:
(1) The arrangement between the various elementary functions must satisfy the previously defined service function and the functional interfaces;

(2) Functional surfaces should be oriented as widely as possible in the same direction.

Once the different configurations have been defined, the objective is to identify possible manufacturing orientations for each modular structure according to the dimensions of the manufacturing machine. For microwave parts, some criteria such as surface quality of functional surfaces of the first order (FSFO) are essential (as shown in paragraph 2.1.2.). As a consequence, it would be beneficial to have manufacturing orientations where the FSFO could be built vertically. However, it sometimes induces an increase in the manufacture price. Finally, pre-oriented modular structures are obtained. If there is no suitable orientation, most of the time the selection of RF candidates should be reviewed. In this case, note that the global design space would certainly change.

It is important to mention that at this stage, external support structures are not discussed because the surfaces - and so the design - do not exist yet as it is representing the volume of propagation which is purely virtual, until section 3.2.4 where it becomes tangible with the mechanical casing.

\subsubsection{Void conceptual design}

The purpose now is now to design 'the void', that is to say the volume of wave propagation. As mentioned in the previous paragraph, elementary design spaces should be 'carved' to get optimised shapes. It is a transitional step in the design of any guided propagation components because most of the product final geometry is defined here. Consequently, almost unlimited creative opportunities brought by AM have to be considered with abandon in this module to be able to break the cognitive barriers. In this way, we propose three different aspects to work on all at the same time without any specific order. One of them relates to the development of design solutions. By saying this we mean focusing exclusively on shapes/solutions. It is only about turning psychological inertia down. To do so, creativity techniques (Rias et al. 2016), TRIZ theory (Altshuller and Seredinski 2004), design catalogues (Roth 2002), feedback, nature observation, etc. are encouraged. Optimisation of RF properties working group allows ensuring the electromagnetic performances either from theoretical optimised geometries existing within the literature, a software optimisation of developed/existing design solutions. 
The last one proposed is related to the AM-conformal embodiment. Existing tools such as design rules or design guidelines can:

(1) Allow design solutions imagined in other working groups to be arranged to coincide with the constraints of $A M$;

(2) Help generate basic solution approaches to be optimised by previously introduced tools.

Also, the de-risking step is crucial before moving to the mechanical and thermal casing. In relation to the pre-orientations identified in section 3.2.2., it is necessary that the internal surfaces of the solutions - resulting from the 'carving' - remain self-supported. As explained in section 2.1.1, as the part is fabricated in a continuous way, if internal support structures were placed inside the part they would be impossible to remove and so the signal would not be able to be transmitted. Note that post-processing - surface treatment and powder removing - should be considered in this void design module. Smooth section change, large radius rounded corners, etc. favour fluid flows, instead of brutal section change, sharp angles, cavities, etc.

Here again, (external) support structures are not mentioned because the void is not a physical object.

Once optimised void solutions are designed according to both RF and AM standard practice, electromagnetic simulations are completed. If they are not consistent with requirements, other void solutions must be contemplated.

\subsubsection{Mechanical and thermal casing}

From the previous module, oriented conceptual models have arisen. Before starting casing, Boolean operations are performed to get the external wrapping. Here again, both optimisation of mechanical/thermal properties and AM-conformal embodiment working groups should be managed at the same time. To achieve an optimised casing while respecting requirements, existing tools can be integrated. For example, lattice structures can be introduced to lighten the whole structure, to help the powder removal along, to get some specific mechanical/thermal properties, etc. Almost all the surfaces being functional, topology optimisation could possibly be considered in some cases but to a certain extent and should be subject to a precise parameterisation.

To be compliant with the constraints of $A M$, the same tools, as those used in the previous paragraph can be employed. The purpose of the mechanical and thermal casing is, on the one hand, to move from a conceptual model (the void) to a physical model, and on the other hand, to minimise the deformations induced by the laser. Therefore, design rules and design guidelines must be used to minimise thermal gradient concentrations (rounded edges and corners, minimal wall thickness, etc.) and to maximise the mechanical resistance (minimal wall thickness, stiffeners integration, etc.).

As soon as the mechanical/thermal casing is done in compliance with the requirements and AM constraints, microwave waveguide parts for AM are obtained. Then, supports are considered and need to be implemented before running the simulations. Once the outer surfaces requiring supports - from thermal and gravity points of view - have been determined, they can be automatically or manually generated. Indeed, as the outer surfaces are not functional, support structures will not affect directly the surface quality of the wave path. However, a lack of support structures could induce some mechanical and thermal deformations resulting in dimensional variations and surface finish damaging.

\subsubsection{Simulation analyses and final manufacturing analyses}

Although manufacturability, mechanical, thermal, electromagnetic performances have normally been ensured throughout the design development by the use of standard procedure, simulations remain essential to give the final green light before manufacturing. In this context, finite elements analyses enables to validate the mechanical and thermal properties, process simulation can provide information about thermal deformations induced by the powder bed fusion, aeraulic test can give access to details about the air flow inside the part - and thus about powder removal etc. If properties of the part are in step with the requirements, the manufacturing strategy - that is to say layer thickness, scanning pattern, hatching space, etc. - is finally adopted. Whatever the chosen strategy, the part will satisfy the mechanical constraints anyway. The objective here is therefore to propose a manufacturing strategy that maximises the mechanical properties while minimising thermal deformations. Microwave waveguide components optimised for additive manufacturing are then obtained.

If the mechanical or process simulations do not satisfy the requirements, modifications need to be operated:

(1) If it concerns thermal deformations, it is possible to move back to the step of support integration. By modifying the location or the shape of the support structures, it is then possible to minimise the thermal deformation occurring during the 
fabrication. If the deformations are still too important, the thermal casing must be adapted;

(2) If it concerns finite element analysis, the mechanical casing needs improvements (for example by incorporating stiffners)

(3) If it concerns powder removal, the mechanical casing must be adjusted (for ex- ample by integrating holes into the shell)

\section{Case study}

For the case study, we chose to present the run of the different steps of the method through the design development of a three-port Ka-band waveguide power divider- combiner (Awang 2013; Brown 2007). The path followed within the methodology for this case study is shown in red in Figure 2.

\subsection{Task clarifications and definitions of the requirements}

As the waveguide power divider is widely used in telecommunications for dividing/combining power from 1 port to $\mathrm{n}$ ports (Awang 2013; Brown 2007), function tree, functional flows, and breakdown structure will not be discussed in this section, only specific requirements. Also, the task flowchart will not be shared in this particular study.

\subsubsection{Technical specifications}

The three ports waveguide powder divider must be operational in Ka-band in signal reception (Rx), that is to say between approximatively 15 and $28 \mathrm{GHz}$. Due to its insertion into whole tactical equipment, the divider must not exceed $70 \times 70 \times 70 \mathrm{~mm}$. Given its operational environment, that is to say corrosion and temperature variations, the part must be made of $\mathrm{Al}$ or $\mathrm{Ti}$.

\subsubsection{Structural specifications}

Functional interfaces are defined by three different parallel flanges, two of which are located in the same plane, at least $1.5 \mathrm{~mm}$ apart. Vertically, plans are $70 \mathrm{~mm}$ apart and the projection on the lower plane of the upper flange must be located between the other two flanges. The dimensions of the flanges are designed to have standardised dimensions defined by ASME/ANSI B16.5 (ASME 2017).

Once the task clarification and the definition of the requirements are completed, the global design space is drawn (Figure 3).

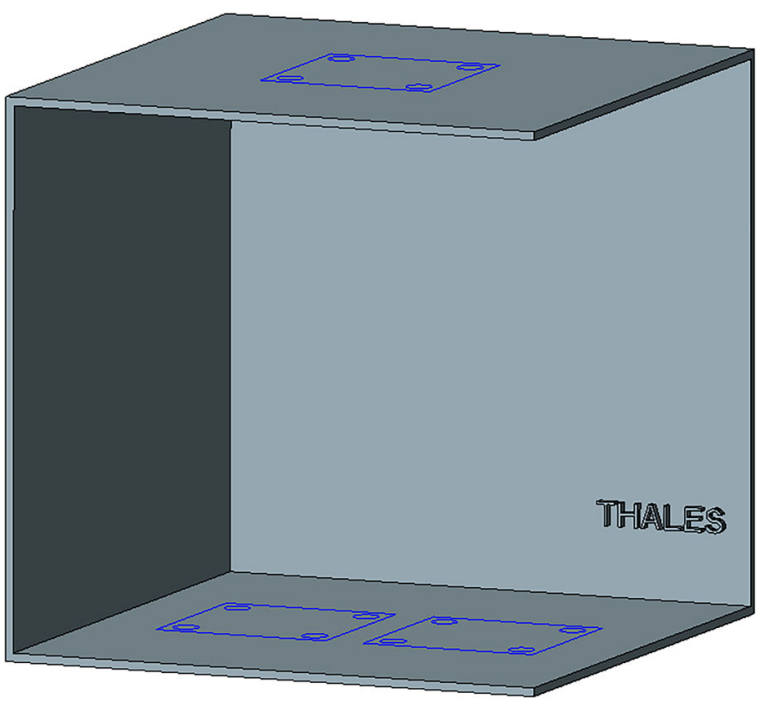

Figure 3. Definition of the global design space and its functional interfaces.

\subsection{Definition of modular structures}

\subsubsection{Elementary design spaces}

Then, the elementary design spaces which are commensurate with the waveguides are defined. In the Ka-band in signal reception, the section of a waveguide is usually $6,318 \times 12,668 \mathrm{~mm}$ (WR-42) with a $1 \mathrm{~mm}$ shell. Therefore, we decided to fix the elementary design space sections to $7 \times 13 \mathrm{~mm}$ (it is important to remind that the objective here is to have a rough idea of what the structure would look like, not to fix the exact dimensions and geometries). Besides, the length of the EDS is adjustable, as long as it is set above $\lambda / 4$ (where lambda is the wavelength of the central frequency), to allow the wave to position itself correctly without causing any harmful effects (Figure 4).

\subsubsection{Selection of RF candidates}

Considering the three EDS and the requirements, it is possible to put them all together into the global design space. Consequently, the three waveguides are selected.

\subsubsection{Spatial layout and pre-orientation}

The objective is to organise into the global design space the three EDS while respecting the requirements of the three-port Ka-band waveguide power divider-combiner, and the functional interfaces. Once these considerations satisfied, two different layouts spring up (Figures 5 and 6).

To decide the best configuration between those two, it is important to consider the FSFO in red in the figures. In Figure 5, as the interfaces between the FSFO are discontinuous, it is clear that a proportion must be inclined to fulfil the condition of continuity. Therefore, all the 


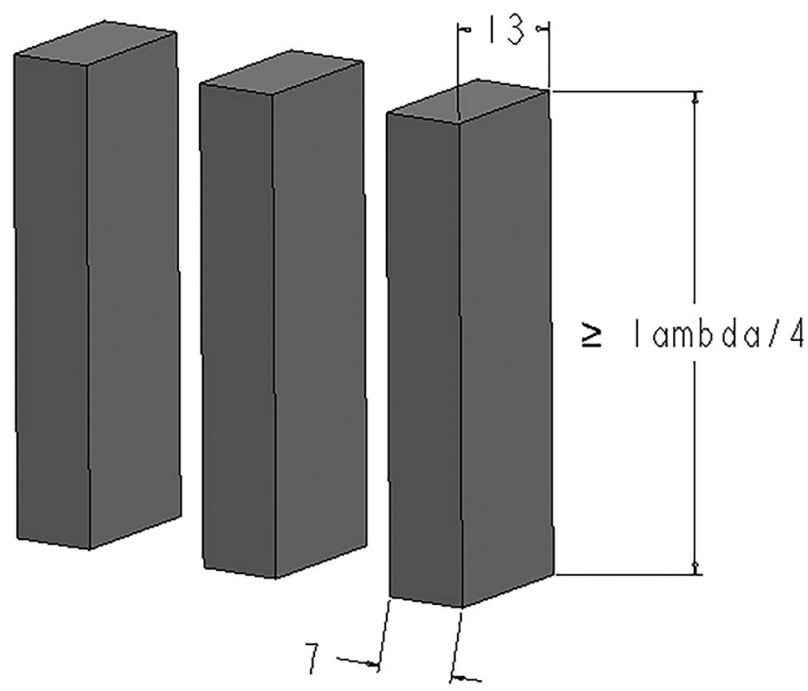

Figure 4. Definition of the three elementary design spaces: a $7 \times$ $13 \mathrm{~mm}$ section with a minimal $\lambda / 4$ length.

FSFO will not have the same inclination and consequently, the same roughness. Quite the reverse, in Figure 6 , the interface is continuous and so all the FSFO will be in the same direction. That is why we chose to consider the second modular structure. The pre-orientation into the manufacturing chamber would be between a (defined by the material so that the FSSO are self-supporting) and 90 degrees in relation towards the build platform, in order to preserve a minimal roughness on the FSFO (Figure 5).

\subsection{Void conceptual design}

\subsubsection{Optimisation of RF properties}

According to a study published by Suzuki and Hosono (1983), the section of the EDS is based on the optimised

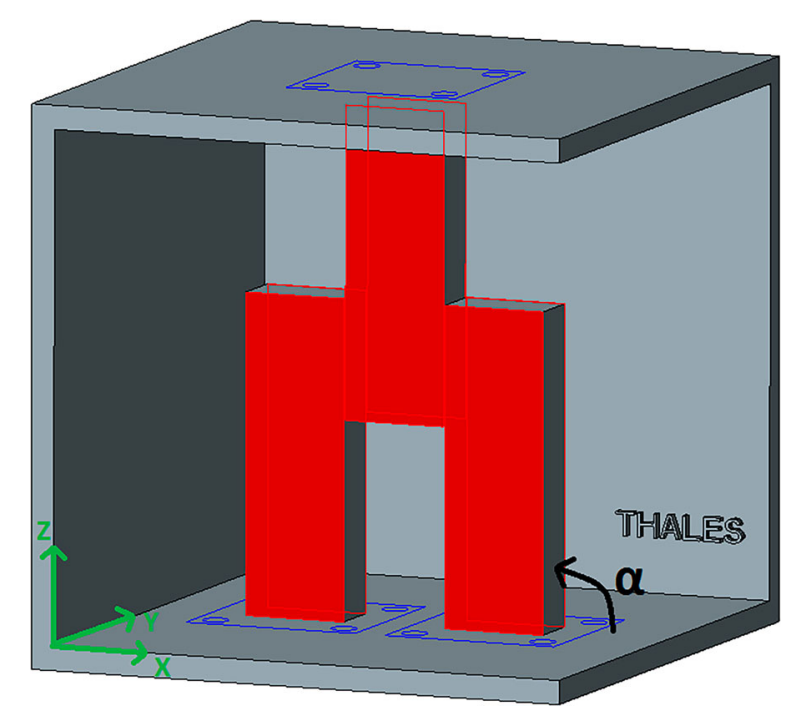

Figure 5. Spatial layout of the elementary design spaces inside the global design space: Modular structure 1.

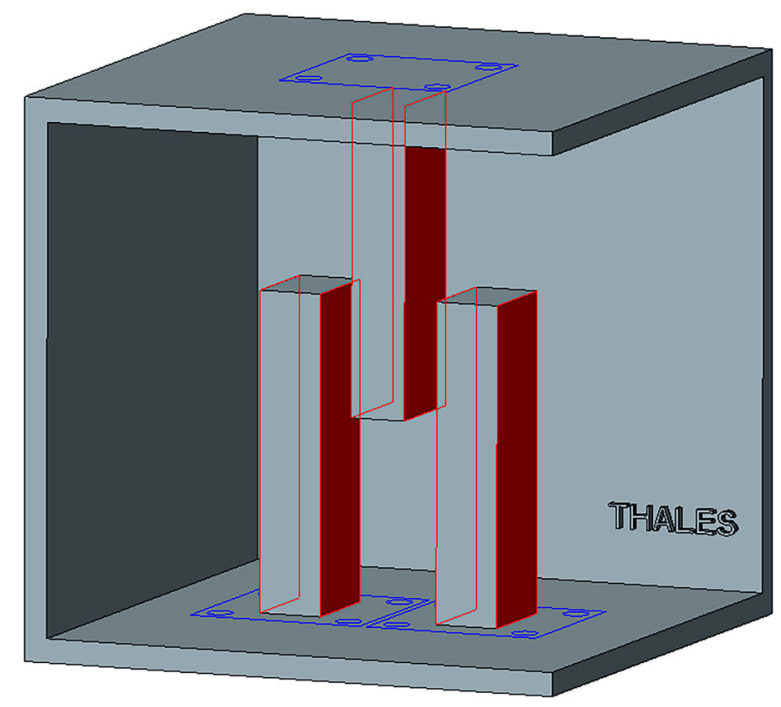

Figure 6. Spatial layout of the elementary design spaces inside the global design space: Modular structure 2.

configuration of waveguide for dominant mode (Figure 7).

\subsubsection{AM-conformal embodiment}

Because the part must be self-supporting to avoid trapped support structures inside the final part, it looks clear that the modular structure in Figure 5 needs an AM conformal embodiment. As suggested within the methodology, the surfaces should then be carved into the EDS to both meet the RF requirements and be selfsupporting.

Just as we have decided to fix the cross-section according to Suzuki's configuration, the objective is then to work on the wave path. Considering the materials we have selected - namely $\mathrm{Ti}$ and $\mathrm{Al}$ - and the functional interfaces, all the surfaces should be leaned between $30^{\circ}\left(45^{\circ}\right.$ for $\mathrm{Al}$ ) and $72,5^{\circ}$ towards the build platform to be self-supporting. To determine the optimised angle in terms of RF performances, incremental simulations have been performed in ANSYS HFSS. It appears that the best results are obtained considering an angle of $68^{\circ}$ towards the build platform. The optimised void design is shown in Figure 8. From that, we can see that all the FS remain in the same direction which proves the importance of defining the modular structure.

As all the surfaces are titled between 68 and 90 degrees towards the build platform, the whole part is self-supporting if it is positioned in the manufacturing chamber at:

(1) 90 degrees, no matter the material chosen among the candidates nominated in Section 4.1.1; 


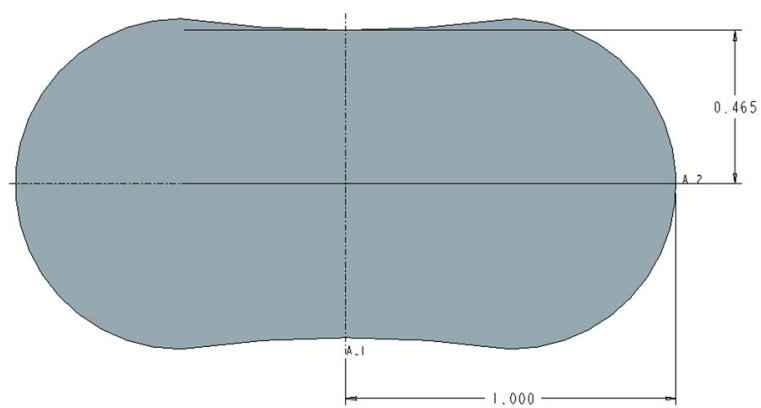

Figure 7. Optimised configuration of waveguide cross section for dominant mode (Suzuki and Hosono 1983).

(2) At $a=45$ degrees for $\mathrm{Al}$;

(3) At $a=30$ degrees for Ti.

Although the main influence of surface quality is located on the FSFO, roughness on the functional surfaces of the second order (FSSO) also has an impact on the quality of the signal transmitted. To ensure minimum roughness on both the FSFO and FSSO but also to avoid a metallisation in post-treatments, we opt for Aluminium and fix the orientation in the manufacturing machine to $90^{\circ}$.

At this stage, the void - representing the propagation channel - is designed knowing it will be self-supporting. However, as it is not a 'physical' object but only a volume of propagation, external support structures cannot be discussed here. They will in the following step where the design becomes a part.

\subsection{Mechanical and thermal casing}

Once the conceptual design is performed, a $1 \mathrm{~mm}$ outer shell is created. As we decided to undertake to

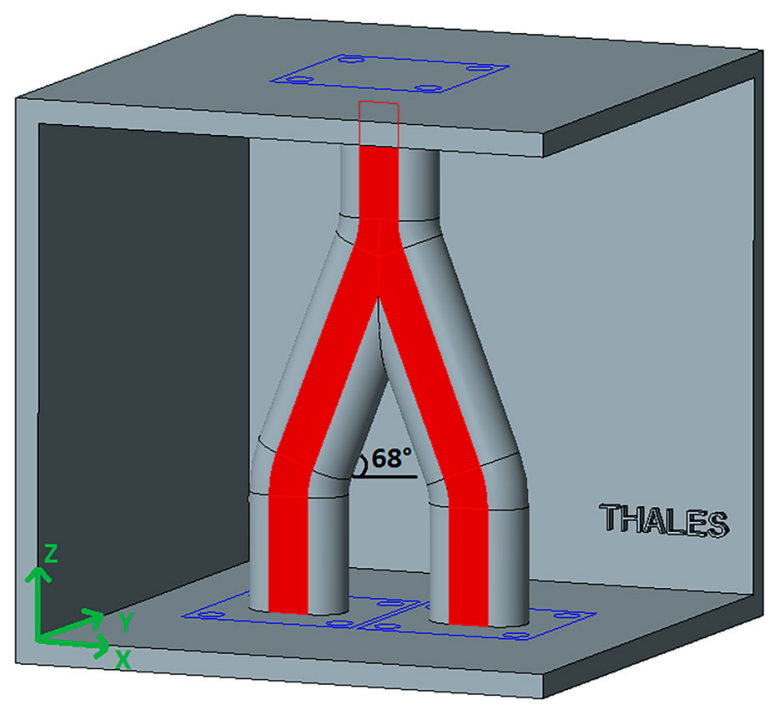

Figure 8. Void conceptual design of the three-port Ka-band waveguide power divider-combiner. manufacture by LBM process, stiffeners are integrated into the part in order to reduce thermal deformations. As the stiffeners do not affect the waveguide properties as they are not located on the signal path. The mechanical casing of the Ka-band divider is shown in Figure 9.

\subsection{Simulations and analyses}

Before running simulations, support structures are integrated to the design. A finite element analysis and a LBM process - assumed strain simulation - are performed in ANSYS Additive Print, as shown in Figure 10. As it can be observed, the greatest displacements are located in the corners of the flanges with an estimated value of 90 microns and the global average value of displacements is around 25 microns. As the dimensional tolerances of the manufacturing process are approximatively 150 microns for Aluminium, we consider that the displacements simulated are negligible and so, acceptable.

Consequently, we consider that the part can be manufactured as designed and the final part is obtained (Figure 11), including the three flanges that need to be machined after manufacturing, to reduce insertion loss.

The development of a three-port Ka-Band waveguide power divider shows a way of taking advantage of the proposed methodology. It consists of five majors steps, all divided into different tools in relation to the design and the electromagnetic, mechanical and thermal performances, that take place in a defined order. In comparison with existing methodologies within the literature, it is formulated to integrate radiofrequency, mechanical and thermal requirements.

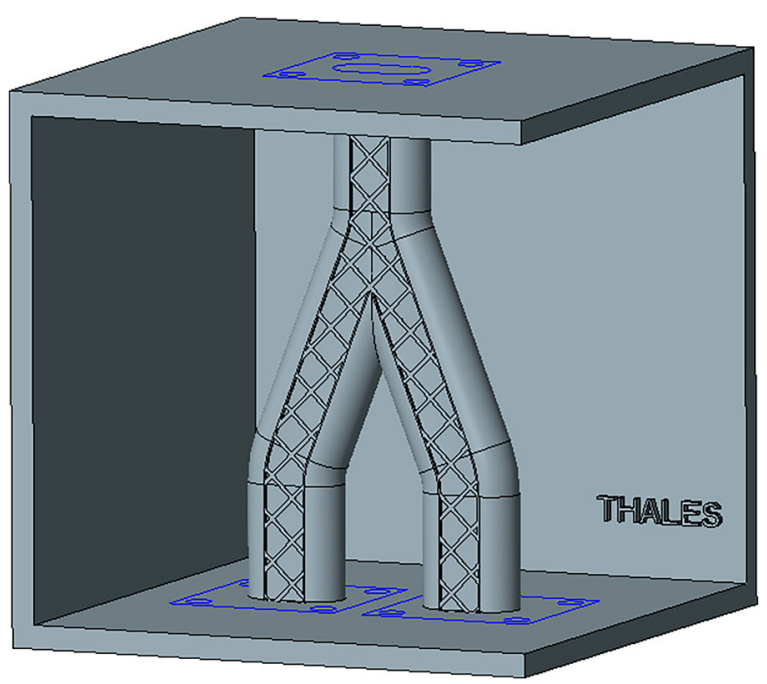

Figure 9. Mechanical casing of the three-port Ka-band waveguide power divider-combiner. 

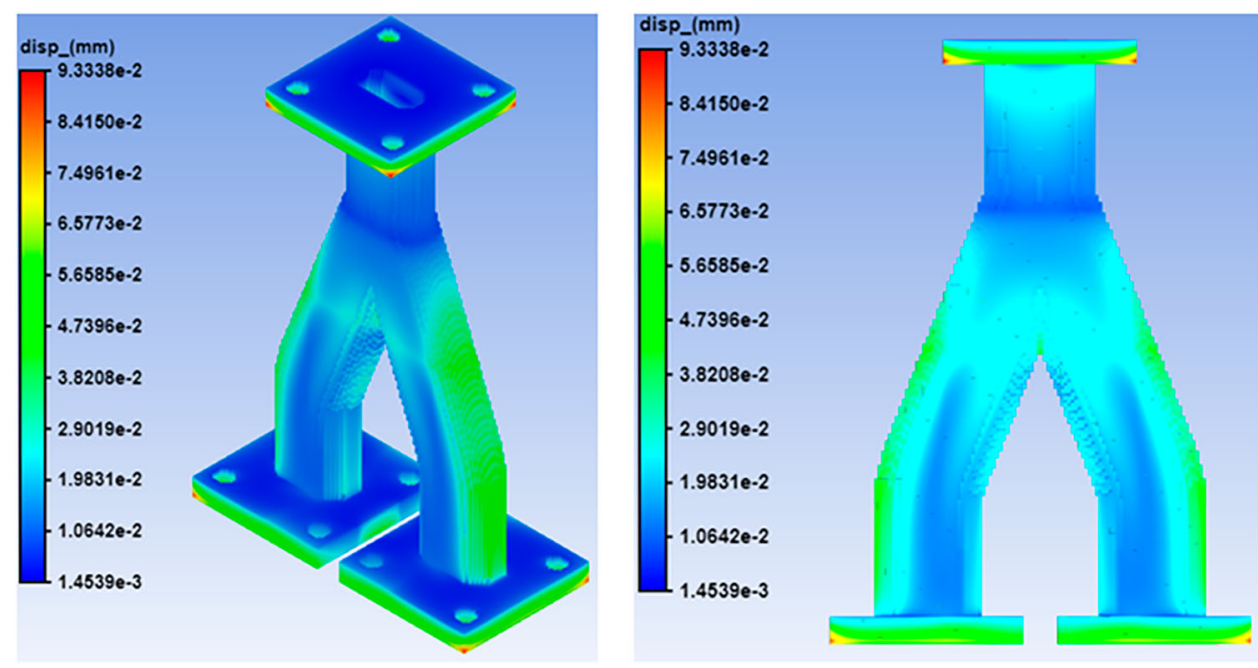

Figure 10. Process simulation analyses: displacements obtained after manufacturing.

In compliance with the research issue, an integrated approach correlated to Pahl and Beitz systematic design procedure seems to correspond to the application domain. By integrating specific tools, this approach guarantees an optimised and manufacturable radiofrequency part by considering both advantages (monolithic, multifunctional and innovative ability) and constraints of additive manufacturing (roughness,

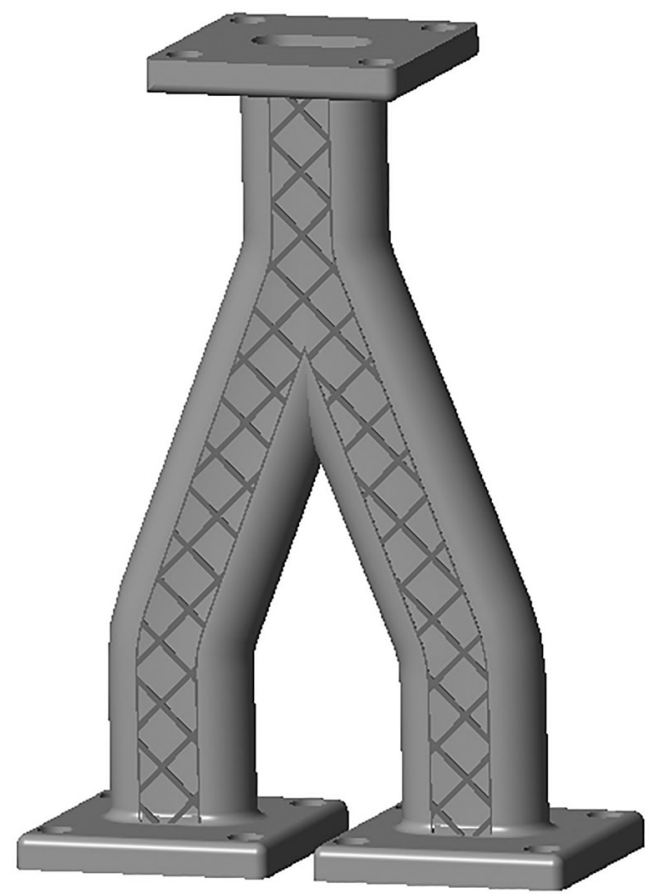

Figure 11. Three-port Ka-band waveguide power divider-combiner optimised for additive manufacturing through the run of the DfAM proposal. supports inside cavities, post-treatment) in relation to radiofrequency requirements.

\section{Conclusions and future research}

In this paper, previous research on DfAM has been reviewed and classified. The limitations brought to light showed the need for a new design methodology dedicated to additive manufactured microwave waveguide components. A new DfAM has been proposed to provide designers a structured framework to fully exploit AM potential while considering specific limitations. Indeed, it allows considering at the same time all the characteristics and rules related to the chosen manufacturing process, whether global or local, and the necessary parameters to be taken on board in order to guarantee the electromagnetic performances defined in the specifications. The proposed method was applied successfully to the design of a three ports Ka-band waveguide power divider.

However, the validation of the proposed DfAM method cannot be based on a single case study although all the different steps have been validated separately. Moreover, to ensure a fully optimised part, some process parameters such as laser power, scanning speed, and hatch spacing need to be considered into the method. Indeed, these process parameters can greatly impact on the final part through an increase of the roughness, important dimensional variations and deformations induced by the laser (Calignano et al. 2013, 2017).

Future work will focus on the influence of process parameters on the surface quality and dimensional variations for both $\mathrm{Al}$ and $\mathrm{Ti}$ materials. This study will lead to the creation of a new block into the framework that 
should ensure a fully optimised part. In addition, the proposed methodology will be run through a more complex case study.

\section{Disclosure statement}

No potential conflict of interest was reported by the authors.

\section{Notes on contributors}

Mathieu François was born in Paris, France, in 1992. In 2016, he received his MSc in Mechanics, Materials and Processes from Arts et Métiers ParisTech School of Engineering with a specialisation in Mechanics and Energetics for Aeronautical and Space Engineering. Since April 2017, he has been working as a Ph.D. candidate at Thales SIX GTS France on the design for additive manufacturing of microwave waveguide components in partnership with Arts et Métiers ParisTech School of Engineering and the French National Center for Scientific Research. The defence of his Ph.D. thesis is planned for April 2020.

Frédéric Segonds is Associate Professor of Mechanical Engineering at Arts et Metiers ParisTech School of Engineering in Paris, France and member of the Product Design and Innovation Laboratory (LCPI). His research interests focus on Creativity and Design With/For/By Additive Manufacturing (CXAM and DXAM).

Mickaël Rivette is Associate Professor of Mechanical Engineering at Arts et Metiers ParisTech School of Engineering in Metz, France and member of the Manufacturing Engineering and Control Laboratory (LCFC). His research interests focus on Design for Additive Manufacturing.

Simon Turpault is Engineering Technologist at Thales SIX GTS France in Cholet, France. His activities focus on Materials, Processes and Additive Manufacturing.

Patrice Peyre is Research Director at Arts et Metiers ParisTech School of Engineering in Paris, France and member of the Processes and Engineering in Mechanics and Materials Laboratory (PIMM) and the French National Center for Scientific Research. His research interests focus on Materials Science, Laser Processes and Additive Manufacturing.

\section{ORCID}

Mathieu François (D) http://orcid.org/0000-0002-2133-1605 Frédéric Segonds (i) http://orcid.org/0000-0001-5677-4257 Mickaël Rivette (D) http://orcid.org/0000-0001-5840-1307

Patrice Peyre (D) http://orcid.org/0000-0002-3679-9622

\section{References}

Altshuller, G., and A. Seredinski. 2004. 40 principes d'innovation: TRIZ pour toutes applications. Broche: A. Seredinski.

ASME. 2017. Pipe Flanges and Flanged Fittings: NPS $1 / 2$ Through NPS 24 Metric/Inch Standard.

Awang, Z. 2013. Microwave Systems Design. Singapore: Springer.
Booth, P., and E. V. Lluch. 2017. "Enhancing the Performance of Waveguide Filters Using Additive Manufacturing." Proceedings of the IEEE 105: 613-619.

Brown, R. 2007. RF/Microwave Hybrids: Basics, Materials and Processes. New York: Springer.

Calignano, F., M. Lorusso, J. Pakkanen, F. Trevisan, E. P. Ambrosio, D. Manfredi, and P. Fino. 2017. "Investigation of Accuracy and Dimensional Limits of Part Produced in Aluminium Alloy by Selective Laser Melting." International Journal of Advanced Manufacturing Technology 88 (1-4): 451-458.

Calignano, F., D. Manfredi, E. P. Ambrosio, L. Iuliano, and P. Fino. 2013. "Influence of Process Parameters on Surface Roughness of Aluminium Parts Produced by DMLS." International Journal of Advanced Manufacturing Technology 67 (9-12): 2743-2751.

Canellidis, V., J. Giannatsis, and V. Dedoussis. 2009. "GeneticAlgorithm-Based Multi- Objective Optimization of the Build Orientation in Stereolithography." The International Journal of Advanced Manufacturing Technology 45 (7): 714-730.

Eder, W. E., and V. Hubka, eds. 1996. Design Science. London: Springer-Verlag.

Guo, C., X. Shang, M. J. Lancaster, and J. Xu. 2015. “A 3-D Printed Lightweight X-Band Waveguide Filter Based on London: Springer-Verlag Resonators." IEEE Microwave and Wireless Components Letters 25 (7): 442-444.

Hirtz, J., R. B. Stone, D. A. McAdams, S. Szykman, and K. L. Wood. 2002. "A Functional Basis for Engineering Design: Reconciling and Evolving Previous Efforts." Research in Engineering Design 13 (2): 65-82.

Hussein, A., L. Hao, C. Yan, R. Everson, and P. Young. 2013. "Advanced Lattice Support Structures for Metal Additive Manufacturing." Journal of Materials Processing Technology 213: 1019-1026.

IEEE Std 521-1984. Standard 521-1976: Letter Designations for Radar-Frequency Bands.

ISO/IEC/IEEE. ISO/IEC/IEEE 24765:2010 Systems and Software Engineering - Vocabulary.

Kempen K., F. Welkenhuyzen, J. Qian, and J. P. Kruth. 2014, April 13. "Dimensional Accuracy of Internal Channels in SLM Produced Parts." In 2014 ASPE Spring Topical Meeting: Dimensional Accuracy and Surface Finish in Additive Manufacturing, 13-16. Berkeley, CA: ASPE - The American Society for Precision Engineering.

Kniepkamp, M., J. Fischer, and E. Abele. 2016. “Dimensional Accuracy of Small Parts Manufactured by Micro Selective Laser Melting." In Proceedings of the 27th Annual International Solid Freeform Fabrication Symposium 2016, 1530-1537. Austin, TX: Verlag nicht ermittelbar.

Kumke, M., K. Dutta, H. Watschke, and T. Vietor. 2016. “A New Methodological Framework for Design for Additive Manufacturing." Virtual and Physical Prototyping 11: 3-19.

Laverne, F., F. Segonds, N. Anwer, and M. Le Coq. 2014. "Assembly Based Methods to Support Product Innovation in Design for Additive Manufacturing: An Exploratory Case Study." Journal of Mechanical Design 137 (12): 121701-121701-8.

Laverne, F., F. Segonds, and P. Dubois. 2016. "Fabrication additive : principes généraux." Techniques de I'Ingénieur TIB633DUO: 1-15.

Leary, M., L. Merli, F. Torti, M. Mazur, and M. Brandt. 2014. “Optimal Topology for Additive Manufacture: A Method for Enabling Additive Manufacture of Support-Free Optimal Structures." Materials \& Design 63: 678-690. 
Morgan, S. P. 1949. "Effect of Surface Roughness on Eddy Current Losses at Microwave Frequencies." Journal of Applied Physics 20: 352-362.

National Aeronautics and Space Administration. 1994. Work Breakdown Structure Reference Guide.

Pahl, G., and W. Beitz. 2007. Engineering Design: A Systematic Approach. London: Springer- Verlag.

Peverini, O. A., M. Lumia, F. Calignano, G. Addamo, M. Lorusso, E. P. Ambrosio, D. Manfredi, and G. Virone. 2017. "Selective Laser Melting Manufacturing of Microwave Waveguide Devices." Proceedings of the IEEE 105 (4): 620-631.

Rias, A. L., C. Bouchard, F. Segonds, and S. Abed. 2016, May. "Design for Additive Manufacturing: A Creative Approach." Paper presented at the DESIGN 2016 14th international design conference, Dubrovnik - Croatia.

Rojas-Nastrucci, E. A., J. Nussbaum, T. M. Weller, and N. B. Crane. 2016. "Meshed Rectangular Waveguide for High Power, Low Loss and Reduced Weight Applications." In 2016 IEEE MTT-S International Microwave Symposium (IMS), 1-4. San Francisco, CA: IEEE.

Roth, K. 2002. Design Catalogues and Their Usage. London: Springer. 121-129.

Sossou, G., F. Demoly, G. Montavon, and S. Gomes. 2018. "An Additive Manufacturing Oriented Design Approach to Mechanical Assemblies." Journal of Computational Design and Engineering 5 (1): 3-18.

Strano, G., L. Hao, R. M. Everson, and K. E. Evans. 2013. "Surface Roughness Analysis, Modelling and Prediction in Selective
Laser Melting." Journal of Materials Processing Technology 213 (4): 589-597.

Suzuki, M., and T. Hosono. 1983. "Optimum Sectional Shape of Dominant Mode Waveguide." IEEE Transactions on Microwave Theory and Techniques 31: 836-841.

Tchoffolo-Talom, F., and S. Turpault. 2017. "Additive Manufacturing for RF Microwave Devices: Design, Performances and Treatments Improvement Evaluations." In International Conference on Electromagnetics in Advanced Applications (ICEAA), 1473-1476. Verona: IEEE.

Thomas, D. 2009. "The Development of Design Rules for Selective Laser Melting." PhD Thesis., University of Wales Institute, Cardiff.

Ulrich, K. T., and S. Eppinger. 2003. Product Design and Development. Singapore: McGraw-Hill Education.

Vandenbroucke, B., and J.-P. Kruth. 2007. "Selective Laser Melting of Biocompatible Metals for Rapid Manufacturing of Medical Parts." Rapid Prototyping Journal 13 (4): 196203.

Wang, R., and W. Cui. 2011. "A Rapid Estimation of the Conductor Loss in the Rectangular Waveguide with Rough Surface." In IEEE 4th International Symposium on Microwave, Antenna, Propagation, and EMC Technologies for Wireless Communications (MAPE), 1791-1793. The Institution of Engineering and Technology.

Zhang, B., and H. Zirath. 2015. "3D Printed Iris Bandpass Filters for Millimetre-Wave Applications." Electronics Letters 51 (22): 1791-1793. 